\title{
Diet Quality Is Associated with a High Newborn Size and Reduction in the Risk of Low Birth Weight and Small for Gestational Age in a Group of Mexican Pregnant Women: An Observational Study
}

\author{
María A. Reyes-López ${ }^{1}$, Carla P. González-Leyva ${ }^{1}$, Ameyalli M. Rodríguez-Cano ${ }^{1}$ (D, \\ Carolina Rodríguez-Hernández ${ }^{1}$, Eloisa Colin-Ramírez ${ }^{2}$ (D) Guadalupe Estrada-Gutierrez $^{3}$ (D), \\ Cinthya G. Muñoz-Manrique ${ }^{1}$ and Otilia Perichart-Perera ${ }^{1, * \mathbb{D}}$
}

\section{check for updates}

Citation: Reyes-López, M.A.;

González-Leyva, C.P.;

Rodríguez-Cano, A.M.

Rodríguez-Hernández, C.;

Colin-Ramírez, E.; Estrada-Gutierrez,

G.; Muñoz-Manrique, C.G.;

Perichart-Perera, O. Diet Quality Is

Associated with a High Newborn

Size and Reduction in the Risk of Low Birth Weight and Small for Gestational Age in a Group of Mexican Pregnant Women: An Observational Study. Nutrients 2021, 13, 1853. https://doi.org/10.3390/ nu13061853

Received: 8 March 2021

Accepted: 24 May 2021

Published: 28 May 2021

Publisher's Note: MDPI stays neutral with regard to jurisdictional claims in published maps and institutional affiliations.

Copyright: (c) 2021 by the authors. Licensee MDPI, Basel, Switzerland. This article is an open access article distributed under the terms and conditions of the Creative Commons Attribution (CC BY) license (https:// creativecommons.org/licenses/by/ $4.0 /)$.
1 Nutrition and Bioprogramming Coordination, National Institute of Perinatology Nacional de Perinatología, Montes Urales 800, Lomas de Virreyes, Mexico City 11000, Mexico; mareyeslo@unal.edu.co (M.A.R.-L.); carlapaty90@hotmail.com (C.P.G.-L.); rocameyalli@gmail.com (A.M.R.-C.); carolina_9494@hotmail.com (C.R.-H.); nutricionperinatal@gmail.com (C.G.M.-M.)

2 Faculty of Medicine and Dentistry, University of Alberta, Edmonton, AB T6G 2E1, Canada; eloisa_colin@yahoo.com.mx

3 Research Direction National Institute of Perinatology, Montes Urales 800, Lomas de Virreyes, Mexico City 11000, Mexico; gpestrad@gmail.com

* Correspondence: otiliaperichart@inper.gob.mx; Tel.: +52-55-55209900 (ext. 402/120)

\begin{abstract}
A high-quality diet during pregnancy may have positive effects on fetal growth and nutritional status at birth, and it may modify the risk of developing chronic diseases later in life. The aim of this study was to evaluate the association between diet quality and newborn nutritional status in a group of pregnant Mexican women. As part of the ongoing Mexican prospective cohort study, OBESO, we studied 226 healthy pregnant women. We adapted the Alternated Healthy Eating Index2010 for pregnancy (AHEI-10P). The association between maternal diet and newborn nutritional status was investigated by multiple linear regression and logistic regression models. We applied three 24-h recalls during the second half of gestation. As the AHEI-10P score improved by 5 units, the birth weight and length increased $(\beta=74.8 \pm 35.0 \mathrm{~g}$ and $\beta=0.3 \pm 0.4 \mathrm{~cm}$, respectively, $p<0.05)$. Similarly, the risk of low birth weight (LBW) and small for gestational age (SGA) decreased (OR: 0.47, 95\%CI: $0.27-0.82$ and OR: 0.55, 95\%CI: 0.36-0.85, respectively). In women without preeclampsia and/or GDM, the risk of stunting decreased as the diet quality score increased (+5 units) (OR: 0.62, 95\%IC: 0.40-0.96). A high-quality diet during pregnancy was associated with a higher newborn size and a reduced risk of LBW and SGA in this group of pregnant Mexican women.
\end{abstract}

Keywords: diet quality; pregnancy; fetal programming; nutritional status; newborn

\section{Introduction}

Nutrition during pregnancy is a key determinant of fetal growth and newborn nutritional status. The effects of intrauterine nutrition remain until later stages of life. Hediger and colleagues [1] found that children who were born underweight or small for gestational age (SGA) tended to have a higher percentage of fat mass, insulin resistance, higher blood pressure, and metabolic alterations in infancy. Likewise, low birthweight, associated with intrauterine growth restriction (IUGR), has been related to a higher incidence of cardiovascular disease and insulin non-dependent diabetes in adult life [2].

The effects of maternal diet on newborn nutritional status have been extensively studied. It is accepted that excessive exposure to glucose and fatty acids in utero may promote a higher concentration of glucose and insulin in the fetus, resulting in an accelerated growth and higher birth weight [3]. In a secondary analysis of the ROLO study, Horan et al. [4], 
noted that the intake of saturated fat at the end of pregnancy was positively associated with neonatal central adiposity. Similarly, a deficient consumption of cobalamin predisposes newborns to a higher adiposity [5].

Diet quality is considered as a matrix of foods and nutrients that acts synergistically and has some relationship with health [6]. During pregnancy, a high-quality dietary pattern includes a high intake of vegetables, fruits, whole grains, legumes, fish, dairy, nuts, and seeds and limits the intake of animal fat, red and processed meat, added sugars, and ultra-processed foods. It may be associated with better perinatal outcomes [7].

According to recent national data, less than half of the Mexican population reported that they usually consume vegetables and eggs. Conversely, almost $86 \%$ of the population consumes sweetened beverages on a regular basis, and one-third consumes unhealthy snacks, sweets, desserts, and ultra-processed foods [8]. Very few research exists reporting diet quality during pregnancy in Hispanic or Mexican women.

Dietary patterns may be determined a priori based on established recommendations. They may also be empirically derived based on statistical technics, with an a posteriori approach [6]. The Alternate Healthy Eating Index (AHEI) is an a priori score to evaluate diet quality and was created as an alternative to the Healthy Eating Index. AHEI includes foods and nutrients that have been associated with chronic disease risk [9]. The most recent version is the AHEI-2010, which includes vegetables, fruits, whole grains, sugar-sweetened beverages, nuts and legumes, red/processed meat, long-chain (n-3) fatty eicosapentaenoic acid (EPA) and docosahexaenoic acid (DHA), sodium, alcohol, and trans and polyunsaturated fatty acids as percentages of energy [10].

An adaptation of the original AHEI score was developed for pregnancy by Rifas and colleagues [11], (AHEI-P). It was composed of nine items that assessed vegetables, fruits, fiber, trans fatty acids, calcium, folate, and iron intake. It also included the ratio of white to red meat intake and the ratio of polyunsaturated to saturated fatty acids intake. The authors found that a higher AHEI-P score was associated with a lower risk of preeclampsia and lower blood glucose levels in healthy pregnant women. Melere and colleagues [12], re-adapted the AHEI-P for Brazilian pregnant women by adding vegetable protein (legumes) and considered calcium intake recommendations. The total score showed a positive correlation with folate, calcium, and iron intake. Ancira and colleagues [13], based on the Mexican Dietary Guidelines and international dietary recommendations, developed the Maternal Diet Quality Score (MDQS). This index includes polyunsaturated fatty acids (PUFAS), added sugars, fruits and vegetables, red meat, low-fat dairy products, legumes, and food high in saturated fat and/or added sugar. They found that a higher adherence to MDQS was associated with a reduced risk of having a low birth weight newborn [13].

While there are different scores that have been used to evaluate diet quality during pregnancy, the vast majority have been developed in high-income countries, thus limiting its applicability in Mexican pregnant women. The MDQS did not include calcium, folate, and iron intake as index items, which are essential nutrients during pregnancy. The aim of this study was to evaluate the association between maternal diet quality during the second half of pregnancy and newborn nutritional status in a group of pregnant Mexican women using a new adaptation of the AHEI-2010.

\section{Materials and Methods}

\subsection{Study Population}

This study is a secondary analysis of an ongoing Mexican prospective cohort study, OBESO (Origen bioquímico y epigenético del sobrepeso y la obesidad) (2017-2020). We included women with a single pregnancy in the first trimester of pregnancy (11 to 13 weeks of gestation), with a pre-gestational body mass index (BMI) $\geq 18.5 \mathrm{~kg} / \mathrm{m}^{2}$, without diabetes mellitus, hypertension, chronic kidney disease, uncontrolled thyroid disease, liver diseases, or HIV. The selected women had three dietary assessments in different moments in the second trimester (described below). We also excluded those women with congenital 
structural malformations in their fetuses and women with chronic use of insulin, metformin, and steroids. The OBESO cohort was approved by the Committees of Ethics, Research and Biosafety of the National Institute of Perinatology (Project. No. 3300-11402-01-575-17).

\subsection{Maternal Characteristics}

The recruitment was carried out at the Maternal-Fetal Medicine Department during the first trimester visit. Trained staff explained the project, invited all women who met the criteria, and collected the informed consent. At this time, the nutritionist made the first nutrition assessment to obtain the baseline characteristics and retrospectively collect information about the pre-gestational body mass index (BMI). During the follow-up visits, which occurred every four to six weeks, we obtained the patients' weight and completed a dietary assessment.

\subsection{Dietary Assessment}

A standardized interviewer applied a multiple-pass $24-\mathrm{h}$ recall at 20 to $24,24.1$ to $28,28.1$ to 34 , and $\geq 34$ gestational weeks. To improve the portion size estimation, the interviewers used food replicas, as well as standard measuring cups, spoons, and glasses. Nutrient analysis was performed with the Food Processor SQL software (version 14.0, Esha Research, Salem, OR, USA). We standardized the recipes and included Mexican foods in the database. The intake of energy, macronutrients, fiber, mono, poly, saturated and trans fatty acids, cholesterol, vitamins A, C, and D, folate, calcium, iron, magnesium, selenium, and zinc was computed from three multiple-pass $24-h$ recalls. Likewise, to establish the usual energy, nutrient, and food groups intake, we considered the three dietary assessments and calculated an average for each item. Subsequently, we computed the AHEI-10P.

\subsection{Alternative Healthy Eating Index-2010 for Pregnancy (AHEI-10P)}

This score was created as an alternative to AHEI-2010 for use during pregnancy [10]. The original index (AHEI-10) includes alcohol and sodium intake. Since alcohol is not recommended during pregnancy, we excluded this item. Regarding the dietary sodium intake, its assessment using dietary tools has numerous biases, and the standard method for its assessment, 24-h urine testing, is not part of the procedures of the OBESO cohort; thus, this item was also excluded [14]. Finally, we included calcium, iron, and folate intake due to their relevance during pregnancy [7]. With the exception of fish, calcium, iron, and folate, all items were scored according to the AHEI-2010 criteria. All components were scored from 0 (worst) to 10 (best). For intermediate values, we used the equations described in Appendix A. The total AHEI-10P score ranged from 0 (lowest diet quality) to 120 (highest diet quality). A description and calculation for each item and scoring criteria are described in Table 1. 
Table 1. The Alternate Healthy Eating Index-2010 for pregnancy (AHEI-10P) scoring method.

\begin{tabular}{|c|c|c|c|}
\hline Component & Food Definition and Serving Size & $\begin{array}{l}\text { Criteria for Minimum } \\
\text { Score (0) }\end{array}$ & $\begin{array}{l}\text { Criteria for Maximum } \\
\text { Score (10) }\end{array}$ \\
\hline Vegetables, servings/d ${ }^{1}$ & $\begin{array}{c}\text { Any type of vegetable in any preparation. One } \\
\text { serving }=1 \text { raw cup or } \frac{1}{2} \text { cup cooked, high in } \mathrm{HCO} \\
(1 \text { cup }=236.59 \mathrm{~g}) \text {. Does not include potato, corn, } \\
\text { or avocado }\end{array}$ & 0 & $\geq 5$ \\
\hline Fruit, servings/d ${ }^{1}$ & $\begin{array}{l}\text { Any natural and whole fruit (not fruit juice). One } \\
\text { Serving = according to the Mexican food exchange } \\
\text { system [15]. }\end{array}$ & 0 & $\geq 4$ \\
\hline Whole grains, g/d ${ }^{1}$ & $\begin{array}{l}\text { Whole grains and whole grain non-refined cereals } \\
\text { were considered (corn tortilla, pozole corn, } \\
\text { popcorn, oats, amaranth, brown rice and pasta, } \\
\text { and granola). One serving = Serving containing } 15 \\
\text { g of HCO, according to the Mexican food exchange } \\
\text { system [15]. }\end{array}$ & 0 & $75^{2}$ \\
\hline $\begin{array}{l}\text { Sugar-sweetened } \\
\text { beverages and fruit juice, } \\
\text { servings } / \mathrm{d}^{1}\end{array}$ & $\begin{array}{l}\text { Includes any industrialized juice or natural juice, } \\
\text { soft drinks, or flavored water powder. One serving } \\
\qquad=240 \mathrm{~mL} \text {. } \\
\text { This does not include coffee or tea with sugar or } \\
\text { flavored waters due to its variable sweetener } \\
\text { content. Besides, it is not equal to the sugar } \\
\text { content of other industrialized beverages. }\end{array}$ & $\geq 1$ & 0 \\
\hline $\begin{array}{l}\text { Nuts and legumes, } \\
\text { servings/d }\end{array}$ & $\begin{array}{l}\text { Legumes include different types of beans, lentils, } \\
\text { and chickpeas. Nuts include walnuts, almonds, } \\
\text { pistachios, peanuts, pine nuts, sunflower seeds, } \\
\text { and peanut butter seeds. One serving of legumes = } \\
\frac{1}{2} \text { cup. One serving of oilseeds and seeds = } 1.5 \\
\text { tablespoons, } 28 \mathrm{~g} \text {, or } 15 \mathrm{~mL} .\end{array}$ & 0 & $\geq 1$ \\
\hline $\begin{array}{l}\text { Red / processed meat, } \\
\text { servings } / \mathrm{d}^{1}\end{array}$ & $\begin{array}{l}\text { Processed meat refers to meats that have } \\
\text { undergone a transformation process through } \\
\text { salting, curing, fermentation, or smoking. Red } \\
\text { meats include beef, lamb, pork, or beef and } \\
\text { poultry viscera. One serving of red meat }=113.4 \mathrm{~g} \\
\text { and processed meat }=42.5 \mathrm{~g} \text {. }\end{array}$ & $\geq 1.5$ & 0 \\
\hline -Trans fat, $\%$ of energy ${ }^{1}$ & $\begin{array}{l}\text { The amount that trans fatty acids contribute to } \\
\text { TCV in percentage. }\end{array}$ & $\geq 4$ & $\leq 0.5$ \\
\hline Fish, servings/d & $\begin{array}{l}\text { Fish is considered the main source of EPA and } \\
\text { DHA fatty acids, so its assessment is comparable } \\
\text { to the direct evaluation of EPA and DHA intake. } \\
\text { This category does not include seafood. The } \\
\text { suggested amount of fish intake was adapted to an } \\
\text { AND of } 250 \mathrm{~g} \text { per week during pregnancy. One } \\
\text { serving }=35.7 \mathrm{~g} / \mathrm{d}(250 \mathrm{~g} / 7=35.7 \mathrm{~g}) \text {. }\end{array}$ & 0 & $\geq 35.7 \mathrm{~g}$ \\
\hline PUFA, $\%$ of energy ${ }^{1}$ & $\begin{array}{l}\text { The amount that polyunsaturated fatty acids } \\
\text { contribute to TCV. }\end{array}$ & $\leq 2$ & $\geq 10$ \\
\hline $\begin{array}{l}\text { Dietary calcium intake, } \\
\mathrm{mg} / \mathrm{d}\end{array}$ & $\begin{array}{l}\text { Calcium is needed for bone formation, fetal } \\
\text { growth, and development. A low calcium intake is } \\
\text { implicated in hypertensive disorders. An adequate } \\
\text { intake during pregnancy is important for } \\
\text { optimizing perinatal outcomes [16]. We } \\
\text { established an average calcium intake through a } \\
\text { serial dietary assessment }(\mathrm{mg} / \mathrm{d}) .\end{array}$ & 0 & $\geq 1000$ \\
\hline
\end{tabular}


Table 1. Cont.

\begin{tabular}{|c|c|c|c|}
\hline Component & Food Definition and Serving Size & $\begin{array}{c}\text { Criteria for Minimum } \\
\text { Score (0) }\end{array}$ & $\begin{array}{c}\text { Criteria for Maximum } \\
\text { Score (10) }\end{array}$ \\
\hline $\begin{array}{c}\text { Dietary iron intake, } \\
\mathrm{mg} / \mathrm{d}\end{array}$ & $\begin{array}{l}\text { Due to hematologic changes and increased needs } \\
\text { during pregnancy, iron is essential. A lack of iron } \\
\text { leads to anemia and affects physical working } \\
\text { capacity, brain function, and behavior. Iron } \\
\text { deficiency increases the risk of adverse perinatal } \\
\text { outcomes. In low-resource settings, iron-deficiency } \\
\text { anemia is prevalent and is often exacerbated by } \\
\text { infectious diseases [7]. We established an average } \\
\text { iron intake through a serial dietary assessment } \\
\text { (mg/d). }\end{array}$ & 0 & $\geq 28$ \\
\hline $\begin{array}{l}\text { Dietary folate intake, } \\
\mathrm{mcg} / \mathrm{d}\end{array}$ & $\begin{array}{l}\text { Folate is critical for normal fetal development. } \\
\text { Folate insufficiency before pregnancy is a proven } \\
\text { risk factor for the development of NTDs and other } \\
\text { congenital malformations. Additionally, folate is } \\
\text { important in women for the prevention of } \\
\text { macrocytic anemia and is implicated in } \\
\text { maintaining cardiovascular health and cognitive } \\
\text { function [7]. We established an average folate } \\
\text { intake through a serial dietary assessment (mcg/d } \\
\text { of DFE). }\end{array}$ & 0 & $\geq 750$ \\
\hline
\end{tabular}

\subsection{Newborn Nutritional Status}

A certified dietitian obtained anthropometric measures within the first 48-72 $\mathrm{h}$ of birth, according to Lohman's technique [17]. We used a Tanita WB-3000 Digital Physicians Scale to measure the weight (Tanita, Arlington Heights, IL, USA), a SECA infantometer model 207 (SECA, Hamburg, Deutschland) to measure the recumbent length, and a SECA measured tape model 212 to measure the head circumference (Hamburg, Deutschland). WHO-2006 and INTER-GROWTH-21St growth references were used for evaluating the weight for age $(\mathrm{W} / \mathrm{A})$, weight for length $(\mathrm{W} / \mathrm{L})$, length for age (L/A), body mass index for age (BMI/A), and head circumference for age $(\mathrm{HC} / \mathrm{A})$ in term and preterm newborns $[18,19]$.

\subsection{Potential Confounders and Intermediate Variables}

Maternal age, pregestational-BMI, maternal gestational weight gain, energy intake, multivitamin use (with folic acid and iron), education level, and number of pregnancies (parity) were obtained using questionnaires that collected data on sociodemographic variables, obstetric history, and detailed information about the pregnancy.

Maternal age: This variable was dichotomized as being adolescent $(<19$ years) or adult ( $\geq 19$ years).

Weight status: Maternal weight was measured at each visit using Lohman's technique with a Seca 813 Digital Scale (SECA, Hamburg, Germany) [17].

Height was measured using Lohman's technique with a Fixed Wall Stadiometer 216 for Infants and Adults (SECA, Hamburg, Germany) [17].

Pregestational BMI was classified as normal (BMI 18.5-24.9 kg/ $\mathrm{m}^{2}$ ), overweight (BMI $\left.25.0-29.9 \mathrm{~kg} / \mathrm{m}^{2}\right)$, or obese (BMI $\left.\geq 30 \mathrm{~kg} / \mathrm{m}^{2}\right)$.

Weight gain was classified as adequate, insufficient, or excessive, according to the gestational age and pregestational-BMI, as recommended by the Institute of Medicine [20].

Total energy intake: Average energy intake was considered as Kcal/d from the $24 \mathrm{~h}$ recalls.

Multivitamin: The use of multivitamins was reported at each visit, and we analyzed only brands that provided folic acid and iron, which was dichotomized as use or not use. 
Education: Level of education was reported by women and was considered as low (elementary school and/or incomplete middle school), medium (completed middle school or high school), or high (technical career, bachelor's degree and/or graduate degree).

Parity: Women were considered nulliparous (no previous pregnancy) or multiparous (one or more previous pregnancies).

Preterm birth was considered as birth at 37 weeks of gestation or less, according to the ultrasound in the first trimester; in cases where no ultrasound was available, we calculated the weeks of gestation according to the last menstrual period.

Preeclampsia was defined as increased systolic and/or diastolic blood pressure $(\geq 140 / 90 \mathrm{mmHg})$, accompanied by proteinuria $(\geq 300 \mathrm{mg} / 24 \mathrm{~h})$, after 20 weeks of gestation in a previously healthy woman [21].

Gestational diabetes mellitus (GDM) was established using the one-step strategy for the oral glucose tolerance test at 24-28 weeks of gestation [22].

Newborn sex: The totality of the characteristics of reproductive structure, functions, phenotype, and genotype, differentiating the male from the female organism [23].

\subsection{Statistical Analysis}

Univariate analysis included the means and standard deviations for normally distributed variables, median and interquartile range for variables with a different distribution, and proportions for categorical variables. We used the quartile categorization of the AHEI$10 P$ score for the bivariate analysis. The maternal baseline characteristics and pregnancy outcomes were described across the quartiles of AHEI-10P. The differences in the AHEI$10 P$ scores according to the maternal characteristics, potential confounders, intermediate variables, and newborn nutritional status were evaluated using the T-student test, U-Mann Whitney test, one-way ANOVA, or Kruskal-Wallis. The chi-square test was used for categorical variables. Post hoc analyses were performed with a Bonferroni test for One-way ANOVA and with the U-Mann Whitney between pairs for non-parametric variables, and the statistical significance was adjusted in order to prevent type I errors $(p<0.008)$. In order to determine the association between diet quality and newborn weight, length, head circumference, BMI, and z-scores of the nutrition indices, we developed multiple linear regression models, including the AHEI-10P score as an independent variable. Likewise, the association between diet quality (AHEI-10P score) and low birth weight, SGA, stunting, low head circumference, being overweight, and obesity was evaluated with multiple logistic regressions models. In order to test the effect of energy intake on the relationship between diet quality and newborn nutritional status, we created an interaction term between total energy intake and diet quality; for models with a significant interaction term, this variable was reported in the results; otherwise, we report results without the interaction term in the model. We excluded preterm newborns when analyzing weight, length, head circumference, and low birth weight. Finally, we stratified the models according to the presence/absence of preeclampsia or gestational diabetes mellitus. The sample size was calculated using the difference between two independent means (birthweight) of the two different groups (high- and low-quality diets), considering a 5\% probability for type I errors $(p<0.05)$ and a statistical power of $20 \%$. The final sample was 196 women [24]. The statistical power was computed according to the effect size approach for linear multiple regression and logistic models. The analyses were performed using the statistical software package, SPSS Statistics (version 22.0, IBM, Mexico City, Mexico). The statistical significance was considered using a $95 \% \mathrm{CI}$ and a $p$ value $<0.05$.

\section{Results}

\subsection{Baseline Characteristics}

We included 405 women-newborn pairs in the cohort study from January 2016 to December 2019. Women were excluded due to a lack of newborn anthropometric measures $(36 \%, \mathrm{n}=148)$ and because the dietary assessment was not available $(7.6 \%, \mathrm{n}=31)$. We studied 226 women-newborn pairs. Most women were adults $(84.5 \%, \mathrm{n}=191)$. The mean 
age was $28.8 \pm 8.1$ years. The mean pregestational-BMI was $26.1 \pm 5.2 \mathrm{~kg} / \mathrm{m}^{2}, 32.7 \%$ $(n=74)$ of which were overweight before pregnancy and 20.8\% $(n=47)$ had obesity. In terms of sociodemographic characteristics, $68.6 \%(n=155)$ were married or lived with a partner, $65.2 \%(\mathrm{n}=144)$ had a high education level, $28.5 \%(\mathrm{n}=63)$ a medium education level, and the remaining $6.3 \%(\mathrm{n}=14)$ had a low education level. Over half of the women were housewives $(66.4 \%, n=150), 23.9 \%(n=54)$ were employees, and $9.7 \%(n=22)$ were students. Regarding parity, $75.7 \%(\mathrm{n}=171)$ were nulliparous.

The mean gestational weight gain in the third trimester ( $34.3 \pm 1.7$ gestational weeks) was $8.8 \pm 5.2 \mathrm{~kg}$, and $33.6 \%(n=76)$ had excessive and 30.5\% $(n=69)$ insufficient weight gain. Regarding adverse pregnancy outcomes, $8.6 \%(\mathrm{n}=19)$ of women had preeclampsia, $10.6 \%(n=24)$ had GDM, 6.6\% $(n=15)$ of newborns were preterm, and $17.3 \%(n=39)$ had low birth weight. Table 2 presents the diet quality score and baseline characteristics according to the AHEI-10P quartiles.

Table 2. Diet quality score, baseline characteristics, and maternal perinatal outcomes according to the AHEI-10P quartiles.

\begin{tabular}{|c|c|c|c|c|c|c|c|}
\hline & \multirow[b]{2}{*}{$\begin{array}{c}\text { Diet Quality Score } \\
\text { AHEI-10P } \\
\text { X } \pm \text { DE }\end{array}$} & \multirow[b]{2}{*}{$\mathbf{P}^{\mathbf{a}}$} & \multicolumn{5}{|c|}{$\begin{array}{c}\text { AHEI-10P Quartiles } \\
\text { n (\%) }\end{array}$} \\
\hline & & & $\begin{array}{c}\text { First } \\
(n=56)\end{array}$ & $\begin{array}{l}\text { Second } \\
(\mathrm{n}=59)\end{array}$ & $\begin{array}{l}\text { Third } \\
(\mathrm{n}=54)\end{array}$ & $\begin{array}{l}\text { Fourth } \\
(n=57)\end{array}$ & $\mathbf{P}^{\mathbf{b}}$ \\
\hline \multicolumn{8}{|c|}{ Maternal age } \\
\hline Adults & $60.7 \pm 12.5$ & \multirow{2}{*}{0.46} & $47(83.9 \%)$ & $46(78.0 \%)$ & $47(87.0 \%)$ & $51(89.5 \%)$ & \multirow{2}{*}{0.35} \\
\hline Adolescents & $59.0 \pm 12.6$ & & $9(16.1 \%)$ & $13(22.0 \%)$ & $7(12.0 \%)$ & $6(10.5 \%)$ & \\
\hline \multicolumn{8}{|c|}{ Pregestational status } \\
\hline Normal & $60.3 \pm 13.1$ & \multirow{3}{*}{0.67} & $25(44.6 \%)$ & $27(45.8 \%)$ & $25(46.3 \%)$ & $28(49.1 \%)$ & \multirow{3}{*}{0.48} \\
\hline Overweight & $61.4 \pm 11.5$ & & $14(25.0 \%)$ & $23(39.0 \%)$ & $19(35.2 \%)$ & $18(31.6 \%)$ & \\
\hline Obesity & $59.2 \pm 14.2$ & & $17(30.4 \%)$ & $9(15.3 \%)$ & $10(18.5 \%)$ & $11(19.3 \%)$ & \\
\hline \multicolumn{8}{|c|}{ Parity } \\
\hline Multiparous & $60.2 \pm 13.2$ & \multirow{2}{*}{0.86} & $17(30.4 \%)$ & $13(22.0 \%)$ & $10(18.5 \%)$ & $15(26.3 \%)$ & \multirow{2}{*}{0.49} \\
\hline Nulliparous & $60.5 \pm 12.7$ & & $39(69.6 \%)$ & $46(78.0 \%)$ & $44(81.5 \%)$ & $42(73.7 \%)$ & \\
\hline \multicolumn{8}{|c|}{ Education level } \\
\hline Low & $63.4 \pm 12.6$ & \multirow{3}{*}{0.56} & $3(5.6 \%)$ & $5(8.6 \%)$ & $2(3.8 \%)$ & $4(7.1 \%)$ & \multirow{3}{*}{0.94} \\
\hline Medium & $61.2 \pm 13.1$ & & $37(68.5 \%)$ & $36(62.1 \%)$ & $36(67.9 \%)$ & $35(62.5 \%)$ & \\
\hline High & $63.0 \pm 13.7$ & & $14(25.9 \%)$ & $17(29.3 \%)$ & $15(28.3 \%)$ & $17(30.4 \%)$ & \\
\hline \multicolumn{8}{|c|}{ Civil status } \\
\hline Single & $57.8 \pm 12.7$ & \multirow{2}{*}{0.03} & $20(35.7 \%)$ & $22(37.3 \%)$ & 17 (31.5\%) & $12(21.1 \%)$ & \multirow{2}{*}{0.23} \\
\hline $\begin{array}{l}\text { Married/consensual } \\
\text { union }\end{array}$ & $61.7 \pm 12.7$ & & $36(64.3 \%)$ & $37(62.7 \%)$ & $37(68.5 \%)$ & $45(78.9 \%)$ & \\
\hline \multicolumn{8}{|c|}{ Occupation } \\
\hline Housewife & $60.2 \pm 12.2$ & \multirow{3}{*}{0.85} & $39(69.6 \%)$ & $34(57.6 \%)$ & $43(79.6 \%)$ & $34(59.6 \%)$ & \multirow{3}{*}{0.18} \\
\hline Employed & $60.5 \pm 14.4$ & & $13(23.2 \%)$ & $16(27.1 \%)$ & $8(14.8 \%)$ & $17(29.8 \%)$ & \\
\hline Student & $61.8 \pm 13.4$ & & $4(7.1 \%)$ & $9(15.3 \%)$ & $3(5.6 \%)$ & $6(10.5 \%)$ & \\
\hline \multicolumn{8}{|c|}{ Multivitamin use } \\
\hline Used & $61.2 \pm 13.0$ & \multirow{2}{*}{0.17} & $40(71.4 \%)$ & $44(75.9 \%)$ & $37(68.5 \%)$ & $46(80.7 \%)$ & \multirow{2}{*}{0.47} \\
\hline Not used & $58.5 \pm 12.1$ & & $16(28.6 \%)$ & $14(24.1 \%)$ & 17 (31.5\%) & $11(19.3 \%)$ & \\
\hline
\end{tabular}


Table 2. Cont.

\begin{tabular}{|c|c|c|c|c|c|c|c|}
\hline & \multirow[b]{2}{*}{$\begin{array}{c}\text { Diet Quality Score } \\
\text { AHEI-10P } \\
\text { X } \pm \text { DE }\end{array}$} & \multirow[b]{2}{*}{$\mathbf{P}^{\mathbf{a}}$} & \multicolumn{5}{|c|}{$\begin{array}{c}\text { AHEI-10P Quartiles } \\
\text { n (\%) }\end{array}$} \\
\hline & & & $\begin{array}{c}\text { First } \\
(n=56)\end{array}$ & $\begin{array}{l}\text { Second } \\
(n=59)\end{array}$ & $\begin{array}{l}\text { Third } \\
(n=54)\end{array}$ & $\begin{array}{l}\text { Fourth } \\
(n=57)\end{array}$ & $\mathbf{P}^{\mathbf{b}}$ \\
\hline \multicolumn{8}{|c|}{ Calcium supplementation } \\
\hline Used & $64.8 \pm 8.3$ & \multirow{2}{*}{0.21} & $1(1.8 \%)$ & $3(5.2 \%)$ & $3(5.6 \%)$ & $6(10.5 \%)$ & \multirow{2}{*}{0.25} \\
\hline Not used & $60.2 \pm 13.0$ & & $55(98.2 \%)$ & $55(94.8 \%)$ & $51(94.4 \%)$ & $51(89.5 \%)$ & \\
\hline \multicolumn{8}{|c|}{ Gestational weight gain } \\
\hline Adequate & $59.7 \pm 12.2$ & \multirow{3}{*}{0.41} & $20(35.7 \%)$ & $25(42.4 \%)$ & $19(35.2 \%)$ & $17(29.8 \%)$ & \multirow{3}{*}{0.51} \\
\hline Insufficient & $62.1 \pm 12.1$ & & $14(25.0 \%)$ & $14(23.7 \%)$ & $19(35.2 \%)$ & $22(38.6 \%)$ & \\
\hline Excessive & $59.6 \pm 14.1$ & & $22(39.3 \%)$ & $20(33.9 \%)$ & $16(29.6 \%)$ & $18(31.6 \%)$ & \\
\hline \multicolumn{8}{|c|}{ Preeclampsia } \\
\hline Present & $57.9 \pm 8.2$ & \multirow{2}{*}{0.19} & $4(7.1 \%)$ & $5(8.5 \%)$ & $9(16.7 \%)$ & $1(1.8 \%)$ & \multirow{2}{*}{0.04} \\
\hline Not present & $60.7 \pm 13.2$ & & $52(92.9 \%)$ & $54(91.5 \%)$ & $45(83.3 \%)$ & $56(98.2 \%)$ & \\
\hline \multicolumn{8}{|c|}{ GDM } \\
\hline Present & $63.2 \pm 10.0$ & \multirow{2}{*}{0.26} & $1(1.8 \%)$ & $7(11.9 \%)$ & $11(20.4 \%)$ & $5(8.8 \%)$ & \multirow{2}{*}{0.01} \\
\hline Not present & $60.2 \pm 13.1$ & & $55(98.2 \%)$ & $52(88.1 \%)$ & $43(79.6 \%)$ & $52(91.2 \%)$ & \\
\hline \multicolumn{8}{|c|}{ Preterm birth } \\
\hline Present & $58.1 \pm 13.5$ & \multirow{2}{*}{0.46} & $4(7.1 \%)$ & $2(3.5 \%)$ & $8(14.8 \%)$ & $1(1.8 \%)$ & \multirow{2}{*}{0.03} \\
\hline Not present & $60.7 \pm 12.8$ & & $52(92.9 \%)$ & $57(96.6 \%)$ & $46(85.2 \%)$ & $56(98.2 \%)$ & \\
\hline \multicolumn{8}{|c|}{ Low birth weight } \\
\hline Present & $60.0 \pm 13.9$ & \multirow{2}{*}{0.82} & $12(21.4 \%)$ & $5(8.5 \%)$ & $14(25.9 \%)$ & $8(14.0 \%)$ & \multirow{2}{*}{0.06} \\
\hline Not present & $60.6 \pm 12.7$ & & $44(78.6 \%)$ & $54(91.5 \%)$ & $40(74.1 \%)$ & $49(86.0 \%)$ & \\
\hline
\end{tabular}

The statistical significance $(p<0.05)$ was tested with the T-student or ANOVA $\left(\mathrm{P}^{\mathrm{a}}\right)$ test for the means and chi-square or Fisher's exact tests $\left(\mathrm{P}^{\mathrm{b}}\right)$ for the frequencies. GDM: gestational diabetes mellitus.

Women that lived with a partner had higher diet quality scores than single women ( $61.7 \pm 12.7$ vs. $57.8 \pm 12.7, p=0.037)$. Compared to the first, second, and third quartiles, women in the highest diet quality group had the lowest frequency of preeclampsia and preterm newborns. Even though the statistical significance was obtained for GDM and low birth weight frequencies, no differences were found between the highest and lowest diet quality groups.

\subsection{AHEI-10P and Nutrients Intake}

Table 3 describes the mean energy and nutrient intake according to the AHEI-10P quartiles.

The energy intake was higher in the highest diet quartile, compared to the lowest diet quality group ( $2043.7 \mathrm{vs} .1723 .5 \mathrm{kcal}$ ). While the macronutrient intakes were higher in the highest quartile, compared to the lowest, in proportion to the total energy, the intake of protein, lipids, and carbohydrates were no different in these groups (Table 3). When adjusted per $1000 \mathrm{kcal}$, the fiber intake was higher in the highest diet quality group, compared to the lowest diet quality group ( $15.2 \mathrm{vs.} 9.5 \mathrm{~g} / \mathrm{d})$; the intake of omega 3 and 6 fatty acids was also higher in women in this diet quartile versus the lowest diet quartile $(0.9 \mathrm{~g} / \mathrm{d}$ vs. 0.6 and $7.2 \mathrm{~g} / \mathrm{d}$ vs. $5.0 \mathrm{~g} / \mathrm{d}$, respectively, $p<0.01$ ) (Table 3). Regarding the micronutrient intake, we found that the intake of vitamins A, C, and D, folate, calcium, magnesium, selenium, iron, and zinc was higher in the highest diet quality group, compared to the lowest diet quality group $(p<0.05)$ (Table 3$)$. 
Table 3. Total energy and nutrient intake during the 2nd half of pregnancy according to the AHEI-10P quartiles.

\begin{tabular}{|c|c|c|c|c|c|c|}
\hline \multirow[b]{2}{*}{ Energy and Nutrients } & \multirow{2}{*}{$\begin{array}{c}\text { Total } \\
(n=226)\end{array}$} & \multicolumn{4}{|c|}{ AHEI-10P Quartiles } & \multirow{2}{*}{${ }^{+} \mathbf{P}$} \\
\hline & & $\begin{array}{c}\text { First } \\
(n=56)\end{array}$ & $\begin{array}{l}\text { Second } \\
(n=59)\end{array}$ & $\begin{array}{l}\text { Third } \\
(n=54)\end{array}$ & $\begin{array}{l}\text { Fourth } \\
(n=57)\end{array}$ & \\
\hline Energy (kcal/d) & $\begin{array}{c}1813.2 \\
(1499.4-2183.8)\end{array}$ & $\begin{array}{c}1723.5 \\
(1443.6-1954.7)\end{array}$ & $\begin{array}{c}1795.9 \\
(1392.7-2085.7)\end{array}$ & $\begin{array}{c}1850.9 \\
(1484.4-2270.1)\end{array}$ & $\begin{array}{c}2043.7 \\
(1623.8-2465.8)\end{array}$ & 0.007 \\
\hline Protein (\%TCV) & $17.2(15.1-19.3)$ & $17.4(15.2-19.3)$ & $17.4(15.4-19.5)$ & $16.6(14.6-20.7)$ & $17.1(15.2-18.7)$ & 0.692 \\
\hline Protein $(\mathrm{g} / \mathrm{d})$ & $80.2 \pm 23.3$ & $74.5 \pm 22.8$ & $78.1 \pm 21.5$ & $81.5 \pm 23.7$ & $86.6 \pm 23.9$ & 0.007 \\
\hline Carbohydrate (\%TCV) & $53.4 \pm 6.3$ & $52.9 \pm 6.7$ & $53.1 \pm 5.9$ & $53.3 \pm 5.7$ & $54.3 \pm 6.7$ & 0.272 \\
\hline Carbohydrate (g/d) & $\begin{array}{c}233.3 \\
(195.4-294.6)\end{array}$ & $\begin{array}{c}218.7 \\
(172.5-274.2)\end{array}$ & $\begin{array}{c}229.0 \\
(188.9-282.2)\end{array}$ & $\begin{array}{c}238.6 \\
(191.1-314.8)\end{array}$ & $\begin{array}{c}255.7 \\
(225.2-337.8)\end{array}$ & 0.001 \\
\hline Fat (\%TCV) & $30.2 \pm 5.2$ & $30.1 \pm 4.9$ & $30.3 \pm 5.2$ & $30.4 \pm 5.0$ & $30.0 \pm 5.7$ & 0.950 \\
\hline Fat $(g / d)$ & $60.4(46.9-75.8)$ & $54.1(42.5-71.1)$ & $58.9(43.0-72.2)$ & $64.1(48.8-82.8)$ & $64.1(47.8-85.4)$ & 0.023 \\
\hline Fiber g/1000 kcal & $11.6(9.2-15.2)$ & $9.5(7.6-11.4)$ & $11.1(8.9-13.8)$ & $12.7(10.5-15.2)$ & $15.2(10.5-17.7)$ & 0.000 \\
\hline Fiber (g/d) & $21.8(16.4-26.9)$ & $15.1(12.7-19.6)$ & $19.3(15.5-24.1)$ & $24.9(20.0-27.7)$ & $27.3(22.4-34.8)$ & 0.000 \\
\hline $\begin{array}{c}\text { Saturated fatty acids } \\
(\% \mathrm{TCV})\end{array}$ & $9.2 \pm 2.2$ & $9.3 \pm 2.3$ & $9.7 \pm 2.3$ & $9.3 \pm 2.1$ & $8.6 \pm 1.8$ & 0.079 \\
\hline $\begin{array}{l}\text { Monounsaturated fatty } \\
\text { acids }(\% \mathrm{TCV})\end{array}$ & $9.5 \pm 2.3$ & $9.2 \pm 2.0$ & $9.5 \pm 2.4$ & $9.3 \pm 2.0$ & $9.5 \pm 2.5$ & 0.518 \\
\hline W-3 fatty acids (g/d) & $0.7(0.5-1.0)$ & $0.6(0.4-0.9)$ & $0.6(0.5-0.9)$ & $0.7(0.5-1.0)$ & $0.9(0.6-1.2)$ & 0.000 \\
\hline W-6 fatty acids (g/d) & $5.8(4.4-7.7)$ & $5.0(4.1-6.7)$ & $5.8(4.3-7.5)$ & $5.8(4.3-7.2)$ & $7.2(5.0-9.2)$ & 0.001 \\
\hline Cholesterol (mg/d) & $\begin{array}{c}260.6 \\
(191.6-356.9)\end{array}$ & $\begin{array}{c}261.2 \\
(174.8-345.7)\end{array}$ & $\begin{array}{c}261.7 \\
(202.1-373.2)\end{array}$ & $\begin{array}{c}234.5 \\
(193.9-346.3)\end{array}$ & $\begin{array}{c}270.5 \\
(201.4-340.0)\end{array}$ & 0.673 \\
\hline Vitamin A (UI/d) & $\begin{array}{c}5879.3(3449.1- \\
11459.4)\end{array}$ & $\begin{array}{c}3805.3(2688.2- \\
6714.0)\end{array}$ & $\begin{array}{c}4687.3 \\
(3018.9-8338.0)\end{array}$ & $\begin{array}{c}8759.8(3745.2- \\
15595.5)\end{array}$ & $\begin{array}{l}9491.6(5862.9- \\
15184.5)\end{array}$ & 0.006 \\
\hline Vitamin C (mg/d) & $\begin{array}{c}114.1 \\
(69.5-181.8)\end{array}$ & $\begin{array}{c}85.7 \\
(51.9-131.0)\end{array}$ & $\begin{array}{c}96.5 \\
(55.3-160.9)\end{array}$ & $\begin{array}{c}142.3 \\
(75.7-192.5)\end{array}$ & $\begin{array}{c}166.0 \\
(91.4-221.5)\end{array}$ & 0.000 \\
\hline Folate $(\mathrm{mcg} / \mathrm{d})$ & $\begin{array}{c}293.6 \\
(223.2-404.0)\end{array}$ & $\begin{array}{c}224.8 \\
(169.9-293.4)\end{array}$ & $\begin{array}{c}258.8 \\
(207.7-326.2)\end{array}$ & $\begin{array}{c}318.2 \\
(273.6-414.3)\end{array}$ & $\begin{array}{c}419.5 \\
(292.7-568.3)\end{array}$ & 0.000 \\
\hline Vitamin D (UI/d) & $\begin{array}{c}139.6 \\
(81.4-200.7)\end{array}$ & $\begin{array}{c}114.5 \\
(56.5-187.6)\end{array}$ & $\begin{array}{c}119.6 \\
(69.7-191.4)\end{array}$ & $\begin{array}{c}144.3 \\
(95.5-214.8)\end{array}$ & $\begin{array}{c}185.3 \\
(112.2-209.4)\end{array}$ & 0.006 \\
\hline Calcium (mg) & $\begin{array}{c}877.2 \\
(685.7-1074.5)\end{array}$ & $\begin{array}{c}765.4 \\
(523.3-991.5)\end{array}$ & $\begin{array}{c}780.8 \\
(641.3-1048.1)\end{array}$ & $\begin{array}{c}950.0 \\
(718.1-1167.8)\end{array}$ & $\begin{array}{c}983.8 \\
(779.4-1140.0)\end{array}$ & 0.000 \\
\hline Iron (mg) & $11.5(9.4-15.1)$ & $10.7(7.2-12.8)$ & $11.1(8.6-12.7)$ & $11.7(10.0-14.9)$ & $15.1(11.2-18.1)$ & 0.000 \\
\hline Magnesium (mg/d) & $\begin{array}{c}279.7 \\
(230.7-341.9)\end{array}$ & $\begin{array}{c}230.9 \\
(183.9-265.4)\end{array}$ & $\begin{array}{c}255.4 \\
(224.6-312.4)\end{array}$ & $\begin{array}{c}294.4 \\
(257.5-362.4)\end{array}$ & $\begin{array}{c}363.2 \\
(285.2-417.5)\end{array}$ & 0.000 \\
\hline Selenium (mcg/d) & $74.4(60.1-90.7)$ & $70.8(53.4-87.0)$ & $75.6(61.9-88.1)$ & $73.0(59.0-90.0)$ & $\begin{array}{c}79.5 \\
(65.7-103.4)\end{array}$ & 0.012 \\
\hline Zinc (mg/d) & $9.3(7.3-11.9)$ & $8.7(6.7-10.8)$ & $8.7(6.6-11.2)$ & $9.9(7.7-11.3)$ & $10.2(8.2-13.0)$ & 0.006 \\
\hline
\end{tabular}

The values are the medians and interquartile range or means \pm SDs. TCV: Total caloric value. ${ }^{\dagger}$ The statistical significance was tested between the first and fourth quartiles with the T-Student or U Mann-Whitney test.

\subsection{Newborn Nutritional Status and AHEI-10P}

\subsubsection{Nutritional Status Alterations According to AHEI-10P}

Male newborns represented 49.1\% $(\mathrm{n}=111)$. The mean birth weight was $2846.7 \pm 427.1 \mathrm{~g}$, the length was $46.5 \pm 2.1 \mathrm{~cm}$, BMI was $13.0 \pm 1.3 \mathrm{~kg} / \mathrm{m}^{2}$, and head circumference was $33.7 \pm 1.4 \mathrm{~cm}$. The mean gestational age at birth was $38.6 \pm 1.4$ weeks. One third of newborns $(30.5 \%, n=69)$ were classified as SGA. Only $1.3 \%(n=3)$ of them presented macrosomia. According to $\mathrm{W} / \mathrm{L}$, the frequency of wasted, risk of overweight, overweight, 
and obese newborns was $1.6 \%(n=4), 16.2 \%(n=30), 6.5 \%(n=12)$, and $0.5 \%(n=1)$, respectively. When using the $\mathrm{BMI} / \mathrm{A}$ index, $1.9 \%(\mathrm{n}=4)$ were wasted, $5.2 \%(\mathrm{n}=11)$ had a risk of being overweight, and $1.4 \%(n=3)$ were overweight. There were no cases of obesity according to BMI/A. Stunting was observed in $34.4 \%(n=77)$ of newborns, and $5.8 \%(n=13)$ of them had an altered head circumference growth. There were no significant differences for weight, length, head circumference, and/or BMI according to the AHEI-10P quartiles. Table 4 describes the nutritional status outcomes according to the AHEI-10P quartiles.

Table 4. Newborn nutritional status according to the AHEI-10P quartiles.

\begin{tabular}{|c|c|c|c|c|c|c|c|c|}
\hline \multirow{2}{*}{$\begin{array}{l}\text { Alterations of } \\
\text { Newborn } \\
\text { Nutritional } \\
\text { Status }\end{array}$} & \multirow[b]{2}{*}{$\begin{array}{c}\text { Total } \\
\text { N (\%) }\end{array}$} & \multirow[b]{2}{*}{$\begin{array}{c}\text { Diet Quality } \\
\text { Score AHEI-10P } \\
\text { X } \pm \text { DE }^{\mathbf{a}}\end{array}$} & \multirow[b]{2}{*}{$p$} & \multicolumn{4}{|c|}{ AHEI-10P Quartiles ${ }^{b}$} & \multirow[b]{2}{*}{$p$} \\
\hline & & & & $\begin{array}{c}\text { First } \\
\text { Quartile } \\
(n=56)\end{array}$ & $\begin{array}{l}\text { Second } \\
\text { Quartile } \\
(n=59)\end{array}$ & $\begin{array}{l}\text { Third } \\
\text { Quartile } \\
(\mathrm{n}=54)\end{array}$ & $\begin{array}{l}\text { Fourth } \\
\text { Quartile } \\
(n=57)\end{array}$ & \\
\hline \multicolumn{9}{|c|}{ Small for gestational age } \\
\hline Present & $69(30.5 \%)$ & $61.2 \pm 14.1$ & \multirow{2}{*}{0.60} & $21(37.5 \%)$ & $11(18.6 \%)$ & $17(31.5 \%)$ & $20(35.1 \%)$ & \multirow{2}{*}{0.12} \\
\hline Not present & $157(69.5 \%)$ & $60.2 \pm 12.3$ & & $35(62.5 \%)$ & $48(81.4 \%)$ & $37(68.5 \%)$ & $37(64.9 \%)$ & \\
\hline \multicolumn{9}{|c|}{ Stunted (L/A) ${ }^{1}$} \\
\hline Present & $77(34.4 \%)$ & $62.0 \pm 13.9$ & \multirow{2}{*}{0.19} & $19(33.9 \%)$ & $16(27.6 \%)$ & $17(32.1 \%)$ & $25(43.9 \%)$ & \multirow{2}{*}{0.31} \\
\hline Not present & $147(65.6 \%)$ & $59.7 \pm 12.3$ & & $37(66.1 \%)$ & $42(72.4 \%)$ & $36(67.9 \%)$ & $32(56.1 \%)$ & \\
\hline \multicolumn{9}{|c|}{ Altered head circumference growth } \\
\hline Present & $13(5.8 \%)$ & $66.3 \pm 10.2$ & \multirow{2}{*}{0.08} & $2(3.6 \%)$ & $1(1.7 \%)$ & $5(9.4 \%)$ & $5(8.9 \%)$ & \multirow{2}{*}{0.21} \\
\hline Not present & $210(94.2 \%)$ & $60.0 \pm 13.0$ & & $54(96.4 \%)$ & $57(98.3 \%)$ & $48(90.6 \%)$ & $51(91.9 \%)$ & \\
\hline \multicolumn{9}{|c|}{ Overweight (W/L) } \\
\hline Present & $12(6.5 \%)$ & $66.3 \pm 10.2$ & \multirow{2}{*}{0.27} & $2(4.3 \%)$ & $2(3.8 \%)$ & $4(9.3 \%)$ & $4(9.3 \%)$ & \multirow{2}{*}{0.55} \\
\hline Not present & $173(93.5 \%)$ & $60.0 \pm 13.0$ & & $45(95.7 \%)$ & $50(96.2 \%)$ & $39(90.7 \%)$ & $39(90.7 \%)$ & \\
\hline \multicolumn{9}{|c|}{ Overweight (BMI/A) } \\
\hline Present & $3(1.4 \%)$ & $60.3 \pm 12.8$ & \multirow{2}{*}{0.96} & $1(1.9 \%)$ & - & $1(2.2 \%)$ & $1(1.8 \%)$ & \multirow{2}{*}{0.76} \\
\hline Not present & $209(98.6 \%)$ & $60.8 \pm 13.0$ & & $51(98.1 \%)$ & $57(100 \%)$ & $45(97.8 \%)$ & $56(98.2 \%)$ & \\
\hline \multicolumn{9}{|c|}{ Obesity (W/L) } \\
\hline Present & $1(0.5 \%)$ & 53.9 & \multirow{2}{*}{0.64} & - & $1(1.9 \%)$ & - & - & \multirow{2}{*}{0.46} \\
\hline Not present & $184(99.5 \%)$ & $59.8 \pm 12.7$ & & $47(100 \%)$ & $51(98.1 \%)$ & $43(100 \%)$ & $43(100 \%)$ & \\
\hline \multicolumn{9}{|c|}{ Macrosomia } \\
\hline Present & $3(1.3 \%)$ & $53.7 \pm 8.3$ & \multirow{2}{*}{0.33} & $2(3.6 \%)$ & - & $1(1.9 \%)$ & - & \multirow{2}{*}{0.28} \\
\hline Not present & $223(98.6 \%)$ & $60.5 \pm 12.8$ & & $54(96.4 \%)$ & $59(100 \%)$ & $53(98.1 \%)$ & $57(100 \%)$ & \\
\hline
\end{tabular}

The statistical significance $(p<0.05)$ was tested with the T-Student test. ${ }^{a}$ Chi-square, or Fisher's exact tests. ${ }^{\mathrm{b}} \mathrm{W} / \mathrm{A}$ : weight for age. L/A: length for age. HC/A: head circumference for age W/L: weight for length. BMI/A: body mass index per age.

\subsubsection{Diet Quality Effect on Anthropometric Markers and Nutritional Status Alterations}

According to linear regression models, for every increase of five units in the AHEI$10 \mathrm{P}$ score, a higher weight, length, and W/A was observed (overall $72.70 \pm 34.3 \mathrm{~g}$, $0.35 \pm 0.17 \mathrm{~cm}$ and $0.17 \pm 0.07 \mathrm{z}$-score, respectively, $p<0.05$; women without preeclampsia and/or GDM: $96.75 \pm 34.71 \mathrm{~g}, 0.53 \pm 0.18 \mathrm{~cm}$ and $0.23 \pm 0.07 \mathrm{z}$-score, respectively, $p<0.01$ ). In women without preeclampsia and/or GDM, the L/A increased $(0.19 \pm 0.09, p=0.03)$. A trend towards a higher head circumference and $\mathrm{HC} / \mathrm{A}$ was observed in newborns of women without preeclampsia and/or GDM $(0.21 \pm 0.12 \mathrm{~cm}, p=0.07$ and $0.16 \pm 0.08$ z-score, $p=0.06$, respectively) (Table 5). 
Table 5. Effect of diet quality on anthropometric markers.

\begin{tabular}{|c|c|c|c|c|c|c|c|c|}
\hline \multirow[b]{2}{*}{ Anthropometric Markers } & \multicolumn{8}{|c|}{ AHEI-10P 1} \\
\hline & B & $\mathrm{EE}$ & B Std & $p$ & \multicolumn{2}{|c|}{$95 \% \mathrm{CI}$} & $\mathbf{R}^{2}$ & $\mathbf{P}^{¥}$ \\
\hline \multicolumn{9}{|c|}{ Overall $(n=226)$} \\
\hline${ }^{+}$Weight $(\mathrm{g})^{2}$ & 72.70 & 34.29 & 0.48 & 0.03 & 5.07 & 140.34 & 0.13 & 0.00 \\
\hline${ }^{\dagger}$ Lenght $(\mathrm{cm})^{2}$ & 0.35 & 0.17 & 0.47 & 0.04 & 0.01 & 0.70 & 0.10 & 0.00 \\
\hline BMI $\left(\mathrm{kg} / \mathrm{m}^{2}\right)$ & 0.03 & 0.03 & 0.06 & 0.33 & -0.03 & 0.10 & 0.05 & 0.02 \\
\hline Head circumference $(\mathrm{cm})^{2}$ & -0.01 & 0.03 & -0.02 & 0.75 & -0.07 & 0.05 & 0.13 & 0.00 \\
\hline${ }^{\dagger} \mathrm{z}$-score $\mathrm{W} / \mathrm{A}$ & 0.17 & 0.07 & 0.53 & 0.01 & 0.03 & 0.32 & 0.08 & 0.00 \\
\hline z-score W /L & 0.00 & 0.03 & 0.01 & 0.87 & -0.06 & 0.07 & 0.003 & 0.40 \\
\hline z-score L/A & 0.00 & 0.02 & 0.00 & 0.99 & -0.05 & 0.05 & 0.02 & 0.18 \\
\hline z-score BMI/A & 0.01 & 0.02 & 0.04 & 0.57 & -0.03 & 0.06 & 0.04 & 0.05 \\
\hline z-score HC/A & -0.00 & 0.02 & -0.02 & 0.73 & -0.05 & 0.04 & 0.04 & 0.03 \\
\hline \multicolumn{9}{|c|}{ Women without preeclampsia or GDM $(n=190)$} \\
\hline${ }^{t}$ Weight $(g)^{2}$ & 96.75 & 34.71 & 0.70 & 0.00 & 28.21 & 165.29 & 0.16 & 0.00 \\
\hline${ }^{\dagger}$ Length $(\mathrm{cm})^{2}$ & 0.52 & 0.18 & 0.71 & 0.00 & 0.15 & 0.90 & 0.15 & 0.00 \\
\hline $\mathrm{BMI}\left(\mathrm{kg} / \mathrm{m}^{2}\right)$ & 0.01 & 0.03 & 0.04 & 0.57 & -0.04 & 0.08 & 0.07 & 0.01 \\
\hline${ }^{\dagger}$ Head circumference $(\mathrm{cm})^{2}$ & 0.21 & 0.12 & 0.47 & 0.07 & -0.02 & 0.44 & 0.10 & 0.00 \\
\hline${ }^{\dagger} \mathrm{z}$-score $\mathrm{W} / \mathrm{A}$ & 0.23 & 0.07 & 0.75 & 0.00 & 0.07 & 0.38 & 0.12 & 0.00 \\
\hline z-score W/L & -0.01 & 0.03 & -0.03 & 0.69 & -0.07 & 0.05 & -0.002 & 0.47 \\
\hline${ }^{+} \mathrm{z}$-score L/A & 0.19 & 0.09 & 0.54 & 0.03 & 0.01 & 0.38 & 0.05 & 0.03 \\
\hline z-score BMI/A & 0.00 & 0.02 & 0.00 & 0.93 & -0.05 & 0.05 & 0.04 & 0.07 \\
\hline${ }^{+}$z-score HC/A & 0.16 & 0.08 & 0.49 & 0.06 & -0.00 & 0.33 & 0.04 & 0.07 \\
\hline
\end{tabular}

Multiple Linear Regression Models. Models adjusted by = maternal age (years), pregestational-BMI (reference = normal weight), maternal weight gain (reference $=$ adequate), energy intake $(\mathrm{kcal} / \mathrm{d})$, multivitamin use (reference $=$ No use), education level $($ reference $=$ low), parity $\left(\right.$ reference $=$ multiparous women), and sex (reference $=$ girls). ${ }^{1}$ Expressed as each five units of the original AHEI-10P score. 2 Preterm newborns excluded. $\mathrm{B}=$ Regression coefficients. $\mathrm{EE}=$ Estandard error. $\mathrm{B}$ std $=$ Estandarized regression coefficients. $\mathrm{P}=p$ value. $95 \% \mathrm{CI}=95 \%$ confidence interval. $\mathrm{R}^{2}=$ adjusted R-squared. $\mathrm{P}^{¥}=$ Model significance. ${ }^{\dagger}$ Models for which the interaction term between diet quality and energy intake was significant $(<0.05)$. AHEI-10P $=$ Alternate healthy eating index for pregnancy, 2010. BMI $=$ Body mass index. $\mathrm{W} / \mathrm{A}=$ Weight for age. $\mathrm{W} / \mathrm{L}=$ Weight for length. $\mathrm{L} / \mathrm{A}=$ Length for age. $\mathrm{BMI} / \mathrm{A}=$ Body mass index for age. HC/A = Head circumference for age. GDM: gestational diabetes mellitus.

The risk of low birth weight decreased as the diet quality increased; for every five units of rise in the AHEI-10P score, the risk was 1.22 lower in all women and 1.27 lower in women without preeclampsia and/or GDM $(p<0.01)$. Likewise, for each five units of rise in the AHEI-10P score, the risk of SGA was 0.92 lower in all women, and it was 1.6 lower in women without preeclampsia and/or GDM $(p<0.01)$ (Table 6). Additionally, in women without preeclampsia and/or GDM, the risk of stunting was 0.6 lower for each 5 units of increase in the AHEI-10P score $(p=0.03)$ (Table 6).

Excessive maternal weight gain was associated with a higher newborn weight ( $\beta=208 \pm 64.2 \mathrm{~g}<0.01), \mathrm{BMI}\left(\beta=0.70 \pm 0.21 \mathrm{~kg} / \mathrm{m}^{2}, p<0.01\right), \mathrm{W} / \mathrm{A}(\beta=0.42 \pm 0.14$ z-score $p<0.01), \mathrm{W} / \mathrm{L}(\beta=0.53 \pm 0.21 \mathrm{z}$-score, $p<0.01)$, and BMI/A $(\beta=0.54 \pm 0.17$ $z$-score, $p<0.01$ ). Compared with an adequate gestational weight gain, insufficient weight gain determined lower values for head circumference and $\mathrm{HC} / \mathrm{A}(\beta=-0.51 \pm 0.20 \mathrm{~cm}$, and $\beta=-0.35 \pm 0.15 \mathrm{z}$-score, respectively, $p<0.05)$. Energy intake determined higher values of newborn $\mathrm{W} / \mathrm{A}$ ( $\beta=0.001 \pm 0.00 \mathrm{z}$-score, $p=0.02)$.

Finally, multivitamin use was associated with a lower risk of newborn overweight or obesity according to BMI/A (OR: 0.14, 95\%CI: 0.02-0.74). 
Table 6. Effect of diet quality on nutritional status alterations.

\begin{tabular}{|c|c|c|c|c|c|c|c|c|}
\hline & \multirow{3}{*}{$\frac{\text { Nutritional Status Alterations }}{{ }^{+} \text {Low birth weight }{ }^{2}}$} & \multicolumn{7}{|c|}{ AHEI-10P 1} \\
\hline & & \multirow{2}{*}{\begin{tabular}{c|} 
B \\
-0.79
\end{tabular}} & \multirow{2}{*}{$\begin{array}{c}\text { OR } \\
0.45\end{array}$} & \multicolumn{2}{|c|}{$95 \% \mathrm{CI}$} & \multirow{2}{*}{$\frac{p}{p}$} & \multirow{2}{*}{$\frac{\mathbf{R}^{2}}{0.17}$} & \multirow{2}{*}{$\begin{array}{c}p ¥ \\
0.07\end{array}$} \\
\hline \multirow{6}{*}{ Overall $(n=226)$} & & & & 0.25 & 0.79 & & & \\
\hline & ${ }^{\dagger}$ SGA & -0.63 & 0.52 & 0.34 & 0.82 & 0.00 & 0.18 & 0.00 \\
\hline & ${ }^{\dagger}$ Stunting & -0.32 & 0.72 & 0.48 & 1.06 & 0.10 & 0.09 & 0.32 \\
\hline & Altered head circumference & 0.19 & 1.20 & 0.94 & 1.54 & 0.13 & 0.18 & 0.25 \\
\hline & Overweight and obesity (W/L) & 0.12 & 1.13 & 0.89 & 1.44 & 0.29 & 0.25 & 0.05 \\
\hline & Overweight and obesity (BMI/A) & 0.20 & 1.22 & 0.88 & 1.69 & 0.22 & 0.46 & 0.00 \\
\hline \multirow{6}{*}{$\begin{array}{l}\text { Women without } \\
\text { preeclampsia or } \\
\text { GDM }(n=190)\end{array}$} & ${ }^{\dagger}$ Low birth weight ${ }^{2}$ & -0.82 & 0.44 & 0.24 & 0.79 & 0.00 & 0.20 & 0.09 \\
\hline & ${ }^{+} \mathrm{SGA}$ & -0.96 & 0.38 & 0.22 & 0.64 & 0.00 & 0.27 & 0.00 \\
\hline & † Stunting & -0.47 & 0.62 & 0.40 & 0.97 & 0.03 & 0.14 & 0.09 \\
\hline & Altered head circumference & 0.15 & 1.16 & 0.88 & 1.54 & 0.28 & 0.17 & 0.51 \\
\hline & Overweight and obesity (W/L) & 0.00 & 1.00 & 0.83 & 1.21 & 0.96 & 0.28 & 0.02 \\
\hline & Overweight and obesity (BMI/A) & 0.14 & 1.15 & 0.82 & 1.59 & 0.40 & 0.47 & 0.00 \\
\hline
\end{tabular}

Logistic regression models. Models adjusted by = maternal age (years), total energy intake (kcal/d), pregestational-BMI category (reference $=$ normal weight), maternal weight gain category (reference = adequate), multivitamin use (reference =No Use), educational level (reference $=$ low), parity (reference $=$ multiparous women), and sex (reference $=$ girls). ${ }^{1}$ Expressed as each five units of the original AHEI-10P score ${ }^{2}$ Preterm newborns excluded. $\mathrm{B}=$ Regression coefficients. $\mathrm{OR}=$ Odds ratio. $95 \% \mathrm{CI}=95 \%$ confidence interval. $\mathrm{P}=p$ value. $\mathrm{R}^{2}=\mathrm{Nagelkerke}$ R-squared. $p^{¥}=$ Model significance. ${ }^{+}$Models for which the interaction term between diet quality and energy intake was significant $(<0.05)$. AHEI-10P = Alternate healthy eating index for pregnancy, 2010. SGA: small for gestational age. $\mathrm{W} / \mathrm{L}=$ Weight for length. BMI $/ \mathrm{A}=\mathrm{Body}$ mass index for age. GDM: gestational diabetes mellitus. W/L: weight for length.

\section{Discussion}

There are few studies evaluating diet quality during pregnancy and its association with newborn nutritional status in Latin America. As far as we know, this is the second study with this purpose in Mexico. We observed that pregnant women with higher diet quality scores (AHEI-10P) had a lower risk of low birth weight and SGA newborns and improved nutritional status markers at birth.

In the previous study conducted in Mexico, using the MDQS, the authors observed a reduced risk of LBW in the highest adherence group, compared to the lowest adherence group (OR: 0.34; 95\%CI: 0.11-0.90) [13]. In other studies, that used the AHEI or pregnancy adaptations of the AHEI, Rifas and colleagues, [11], showed a lower risk of SGA in women with a high-quality diet score (OR: $0.92,95 \%$ CI: 0.82-1.02). Similar results were found in a secondary analysis of the prospective cohort, "New Hampshire Birth Cohort Study" [25]. Rodríguez and colleagues, [24], applied an adapted version of the AHEI-2002, and they observed that birth weight and length was higher in women in the fifth diet quality quintile, compared with the lowest quintile ( $\beta=114.1 \mathrm{~g}$; $95 \% \mathrm{CI}$ : $27.1-201.2 \mathrm{~g}$ and $\beta=0.41 \mathrm{~cm} ; 95 \% \mathrm{CI}$ : $0.03-0.80 \mathrm{~cm}$ ). González and colleagues, [26], observed that for each unit of increase in the score of AHEI-10, the W/A z-score increased by 0.01 (95\%CI: 0.002-0.02); however, when the models were adjusted, the statistical significance was lost. Similar results have been reported using other diet quality indices. In an analysis of the Australian Longitudinal Study on Women's Health, Gresham and colleagues [27], found that, compared with women in the first quintile, those in the fifth quintile of the Australian recommended food score showed a lower risk of low birth weight (OR $=0.4 ; 95 \% \mathrm{CI}$ : $0.2-0.9)$. In a study in two population-based mother-child cohorts in Spain and Greece, adherence to the Mediterranean diet pattern, using an a priori score, was evaluated. Women with a high adherence had a lower risk of delivering a growth-restricted newborn (RR: 0.5 ; 95\%CI: 0.3-0.9). In smoking mothers, a higher adherence to the Mediterranean diet pattern increased weight and length at birth (Atlantic cohort $\beta=319 \pm 124.3 \mathrm{~g}$ and $\beta=1.3 \pm 0.6 \mathrm{~cm}$, respectively and Mediterranean cohort $\beta=200 \pm 81.5 \mathrm{~g}$ and $\beta=0.8 \pm 0.4 \mathrm{~cm}$, respectively) [28]. 
Our results showed that a high-quality diet was related with a greater intake of fiber, omega 3 and 6 fatty acids, vitamins A, C, and D, folate, calcium, iron, magnesium, selenium, and zinc. Dietary patterns involve a matrix of different foods that contain a number of nutrients; many of them are correlated, so it is difficult to separate their effects. However, some of these nutrients are associated with an improvement in neonatal nutrition status [29]. Fiber intake during pregnancy is important for both the mother's health and fetal growth, and it has been associated with a higher birth weight [30]. Omega3 long chain polyunsaturated fatty acids, in particular, have been associated with a longer gestation, higher birth weight, and less preterm birth [31]. Additionally, essential fatty acids are crucial to fetal development, particularly for cell membranes and the brain [32]. Maternal intakes of vitamins $\mathrm{C}$ and $\mathrm{D}$ and folate have been associated with higher values for length at birth. Similarly, vitamins A and D intakes have been associated with a higher head circumference in a Japanese cohort [33]. Iron supplementation appears to increase birth weight through an increase in maternal hemoglobin concentrations in the third trimester [34]. Finally, folate, vitamin A, C, and D, magnesium, selenium, and zinc have fetal programming implications that, in turn, are closely related with nutrition status at birth [2].

Besides diet quality, gestational weight gain was another factor associated with a higher newborn body mass. An excessive weight gain was related with higher values of newborn weight and BMI, and it was a protecting factor of SGA. In a population-based cohort study in the United States, Ludwing and colleagues [35], found that newborns of women who gained more than $24 \mathrm{~kg}$ during pregnancy were $148.9 \mathrm{~g}$ (95\%CI: 141.7-156.0 g) heavier at birth than were infants of women who gained 8-10 kg. In a systematic review, Goldstein and colleagues, [36], found that a weight gain below IOM recommendations was related to a higher risk of SGA (OR: 1.53, 95\%CI: 1.44-1.64, I2 = 82.8\%).

Like excessive weight gain, energy intake was positively associated with weight and length at birth. Crume and colleagues, [37], found that newborn fat mass was increased by $4.2 \mathrm{~g}$ and $2.9 \mathrm{~g}$ for each $100 \mathrm{kcal}$ from fat and carbohydrates, respectively. While the association between maternal energy intake and length at birth has been less frequently studied, Gala and colleagues, [38], found a significantly positive correlation between percentage of energy intake recommendation (RDA) and length at birth.

Another factor that was a determinant of newborn nutritional status was education level. Our results showed that women with a medium education level had a lower risk of neuro-developmental risk. In the same way, in a secondary analysis of the Generation $\mathrm{R}$ Study, it was found that head circumference in the first, third, and sixth month of age was lower in infants of women with a low versus those with a high education level [39]. This is important, considering that $\mathrm{HC} / \mathrm{A}$ is a chronic nutritional status index, and lower education levels may be related with nutrition inequalities. Multivitamin use (including iron and folic acid) also determined a lower risk of newborn overweight or obesity. Contrary to our results, in a population-based cohort of women without GDM, Hua and colleagues, [40], observed that women that used iron and folic acid supplements were more likely to deliver a macrosomic or LGA infant (OR: 1.32, 95\%CI: 1.08-1.49 and OR: 1.42, 95\%CI: 1.24-1.61, respectively), as compared with women who did not take supplements. It should be noted that multivitamin use in our study was heterogeneous, and we did not control the dose, administration, duration, and/or nutrient composition.

The development and validation of a diet quality index carries some challenges. First, there is no standard reference for diet quality assessment; and second, dietary assessment has a series of biases that make it difficult to validate. We adapted the Alternate Healthy Eating Index-2010 for use during pregnancy (AHEI-10P). We believe that this version of AHEI is applicable in the Mexican population, considering the high prevalence of coronary heart disease and diabetes, and because it includes different food groups that provide different relevant nutrients in the prenatal stage [41].

In order to guarantee consistency and reduce measurement bias, interviewers were trained with a standardized methodology, and the multiple-pass version of the 24-h recall 
was used in three occasions to gain a closer view of the usual intake. The multiple-pass version of the 24-h recall reduces memory and portion size estimation error and may aid in providing a better food description [42]. In addition, the diet quality score was positively associated with the intake of healthy nutrients (fiber, magnesium, and folate), supporting construct validity.

As in any other dietary assessment study, heterogeneity is present. Items and cutoff points that integrate diet quality indices are not standardized, considering different food groups and different ratings systems; in addition, the dietary assessment method used can also vary (i.e., 24-h record, food frequency). The database used for analyzing nutritional composition is another source of variability. We used the Food Processor Nutrition Analysis Software (SQL). This program uses an extensive database (including some data from Mexico) and allows for the inclusion of new foods or recipes. Finally, in the case of maternal diet quality, the moment during pregnancy in which a dietary assessment is made differs among studies.

To our knowledge, this is the first study that adapted the AHEI-10P for use in Mexican pregnant women, demonstrating that a high-quality diet is not only associated with a lower risk of chronic diseases, but also with better perinatal outcomes. This study adds to the limited literature on diet quality during pregnancy in low-income countries. The estimated effects in this study reached a statistical power greater than 80\%, except for BMI, BMI/A, $\mathrm{W} / \mathrm{L}, \mathrm{L} / \mathrm{A}$, and $\mathrm{HC} / \mathrm{A}$. Even though more research is necessary to confirm our findings, this study shows that diet quality assessment during pregnancy could contribute to the implementation of timely nutritional strategies that may contribute to a lower incidence of low birth weight and SGA newborns.

Our study has some weaknesses that should be addressed. While we used several 24-h recalls for estimating dietary intake, it is possible that individual and inter-individual dietary intake variations were not completely measured, and bias may therefore be an issue $[43,44]$. For the significant effect of diet quality on newborn L/A in the group of women without preeclampsia and/or GDM, the statistical power was low $(53 \%)$. The relatively small sample size may have introduced a type II error. We did not consider physical activity, intergenesic period, or smoking habits as factors that can determine newborn nutrition status, and we did not consider anemia or pregnancy resolutions [45]. All these aspects should be considered in future studies.

\section{Conclusions}

A high-quality diet during pregnancy was associated with a higher newborn weight, length, and reduced risk of low birth weight and SGA. Women who did not develop preeclampsia and/or GDM also showed this association and had a lower risk of stunting. AHEI-10P is an alternative for evaluating diet quality in pregnant women, focusing on important nutrients for maternal and fetal health. More studies evaluating diet (quantity and quality) and its effects on newborn nutrition status in developing countries are necessary.

Author Contributions: Conceptualization, O.P.-P. and M.A.R.-L.; methodology, A.M.R.-C., C.G.M.M., C.P.G.-L., C.R.-H.; formal analysis, M.A.-R.L., E.C.-R.; investigation, M.A.R.-L., O.P.-P.; resources, O.P.-P.; data curation, C.G.M.-M., A.M.R.-C., C.P.G.-L., C.R.-H.; writing-original draft preparation, M.A.R.-L., E.C.-R.; writing-review and editing, O.P.-P., M.A.R.-L.; supervision, O.P.-P.; project administration, G.E.-G., O.P.-P.; funding acquisition, G.E.-G., O.P.-P. All authors have read and agreed to the published version of the manuscript.

Funding: This research was funded by the Instituto Nacional de Perinatología (No. 3300-11402-01575-17) and FOSISS-CONACyT (No. 2015-3-261661).

Institutional Review Board Statement: The study was conducted according to the guidelines of the Declaration of Helsinki and approved by the Institutional Review Board (Ethics Committee) at the INSTITUTO NACIONAL DE PERINATOLOGIA (No. 3300-11402-01-575-17).

Informed Consent Statement: Informed consent was obtained from all subjects involved in the study. 
Data Availability Statement: Not applicable.

Acknowledgments: We thank the National Council of Science and Technology (CONACYT) for supporting M.A.R.L in her academic training during her Master's and Doctorate Degrees at the Instituto Nacional de Salud Pública and Universidad Nacional Autónoma de México (CVU number: 485357).

Conflicts of Interest: O.P.P and A.R.C. are speakers/consultants of the Nestle Nutrition Institute in Mexico. O.P.P is a consultant of the Danone Institute. No conflict of interest exists regarding this study. The other authors declare no conflict of interest.

\section{Appendix A}

Methodology for scoring intermediate items of AHEI-10P

- For vegetables, fruits, whole grains, nuts and legumes, fish, calcium, iron, and folate items:

$$
\frac{\text { Score }=(\text { Ingestedquantity } \times 10)}{\text { Criteriaformaximumscore }}
$$

- For sugar-sweetened beverages and fruit juice, red/processed meat, and trans fatty acids:

$\underline{\text { Score }=10-(\text { Ingestedquantity } \times 5)}$

(Criteriaforminimumscore)

$$
2
$$

- For scoring polyunsaturated fatty, we created a scale based on the percentage of total

\begin{tabular}{|c|c|}
\hline$\% \mathrm{TCV}$ & Score \\
\hline 2 & 0 \\
\hline 2.5 & 0.6 \\
\hline 3 & 1.25 \\
\hline 3.5 & 1.9 \\
\hline 4 & 2.5 \\
\hline 4.5 & 3.1 \\
\hline 5 & 3.8 \\
\hline 5.5 & 4.4 \\
\hline 6 & 5 \\
\hline 6.5 & 5.6 \\
\hline 7 & 6.3 \\
\hline 7.5 & 6.9 \\
\hline 8 & 7.5 \\
\hline 8.5 & 8.4 \\
\hline 9 & 8.8 \\
\hline 9.5 & 9.4 \\
\hline 10 & 10 \\
\hline
\end{tabular}
caloric value (TCV):

\section{References}

1. Hediger, M.L.; Overpeck, M.D.; Kuczmarski, R.J.; McGlynn, A.; Maurer, K.R.; Davis, W.W. Muscularity and fatness of infants and young children born small- or large-for-gestational-age. Pediatrics 1998, 102, E60. [CrossRef]

2. Visentin, S.; Grumolato, F.; Nardelli, G.B.; Di Camillo, B.; Grisan, E.; Cosmi, E. Early origins of adult disease: Low birth weight and vascular remodeling. Atherosclerosis 2014, 237, 391-399. [CrossRef] [PubMed]

3. Agosti, M.; Tandoi, F; Morlacchi, L.; Bossi, A. Nutritional and metabolic programming during the first thousand days of life. La Pediatr. Med. Chir. 2017, 39, 157. [CrossRef] [PubMed] 
4. Horan, M.K.; McGowan, C.A.; Gibney, E.R.; Donnelly, J.M.; McAuliffe, M.F. Maternal low glycaemic index diet, fat intake and postprandial glucose influences neonatal adiposity—secondary analysis from the ROLO study. Nutr. J. 2014, 1, 13-78. [CrossRef]

5. Yajnik, C. Nutritional control of fetal growth. Nutr. Rev. 2006, 64, S50-S51. [CrossRef]

6. Waijers, P.M.C.M.; Feskens, E.J.M.; Ocké, M.C. A critical review of predefined diet quality scores. Br. J. Nutr. 2007, 97, 219-231. [CrossRef]

7. Hanson, M.A.; Bardsley, A.; De-Regil, L.M.; Moore, S.E.; Oken, E.; Poston, L.; Ma, R.C.; McAuliffe, F.M.; Maleta, K.; Purandare, C.N.; et al. The International Federation of Gynecology and Obstetrics (FIGO) recommendations on adolescent, preconception, and maternal nutrition: "Think Nutrition First". Int. J. Gynecol. Obstet. 2015, 131, S213. [CrossRef]

8. Shamah-Levy, T.; Vielma-Orozco, E.; Heredia-Hernández, O.; Romero-Martínez, M.; Mojica-Cuevas, J.; Cuevas-Nasu, L.; SantaellaCastell, J.A.; Rivera-Dommarco, J. Encuesta Nacional de Salud y Nutrición 2018-19: Resultados Nacionales; Government of Mexico: Cuernavaca, Mexico, 2020.

9. McCullough, M.L.; Feskanich, D.; Stampfer, M.J.; Giovannucci, E.L.; Rimm, E.B.; Hu, F.B.; Spiegelman, D.; Hunter, D.J.; Colditz, G.A.; Willett, W.C. Diet quality and major chronic disease risk in men and women: Moving toward improved dietary guidance. Am. J. Clin. Nutr. 2002, 76, 1261-1271. [CrossRef] [PubMed]

10. Chiuve, S.E.; Fung, T.T.; Rimm, E.B.; Hu, F.B.; McCullough, M.L.; Wang, M.; Stampfer, M.J.; Willett, W.C. Alternative dietary indices both strongly predict risk of chronic disease. J. Nutr. 2012, 142, 1009-1018. [CrossRef] [PubMed]

11. Rifas-Shiman, S.L.; Rich-Edwards, J.W.; Kleinman, K.P.; Oken, E.; Gillman, M.W. Dietary Quality during Pregnancy Varies by Maternal Characteristics in Project Viva: A US Cohort. J. Am. Diet. Assoc. 2009, 109, 1004-1011. [CrossRef]

12. Melere, C.; Hoffmann, J.F.; Nunes, M.A.; Drehmer, M.; Buss, C.; Ozcariz, S.G.; Soares, R.M.; Manzolli, P.P.; Duncan, B.B.; Camey, S. Healthy eating index for pregnancy: Adaptation for use in pregnant women in Brazil. Rev. Saude Publica 2013, 47, 20-28. [CrossRef] [PubMed]

13. Ancira-Moreno, M.; Neill, M.S.O.; Angel, J.; Batis, C.; Rodríguez, S.; Sánchez, B.N.; Castillo-Castrejón, M. Dietary patterns and diet quality during pregnancy and low birthweight: The PRINCESA cohort Study design. Matern. Child Nutr. 2020, 16, e12972. [CrossRef] [PubMed]

14. Leiba, A.; Vald, A.; Sc, M.; Peleg, E.; Ph, D.; Shamiss, A.; Grossman, E. Does dietary recall adequately assess sodium, potassium, and calcium intake in hypertensive patients? Nutrition 2005, 21, 462-466. [CrossRef]

15. Pérez, L.A. P.G.B.C.B. Mexican Food Exchange System; Pérez Lizaur, A.B., Palacios Gónzales, B.C.B.A., Eds.; Ogali: Ciudad de México, México, 2008.

16. WHO Guidelines Approved by the Guidelines Review Committee. WHO Recommendation: Calcium Supplementation during Pregnancy for the Prevention of Pre-Eclampsia and Its Complications; WHO: Geneva, Switzerland, 2018.

17. Lohman, T.G.; Roche, A.; Martorell, R. (Eds.) Anthropometric Standardization Reference Manual; Human Kinetics Books: Champaign, IL, USA, 1988.

18. World Health Organization. The WHO Child Growth Standards; WHO: Geneva, Switzerland, 2006.

19. Villar, J.; Giuliani, F.; Bhutta, Z.A.; Bertino, E.; Ohuma, E.O.; Ismail, L.C.; Barros, F.C.; Altman, D.G.; Victora, C.; Noble, J.A.; et al. Postnatal growth standards for preterm infants: The Preterm Postnatal Follow-up Study of the INTERGROWTH-21 st Project. Lancet Glob. Health 2015, 3, e681-e691. [CrossRef]

20. Rasmussen, K.M.; Yaktine, A.L.; Comitee to Reexamine IOM Pregnancy Weight Guidelines; Institute of Medicine (US); National Research Council (US). Weight Gain During Pregnancy; National Academies Press (US): Washington, DC, USA, 2009; ISBN 9780309131131.

21. Sircar, M.; Thadhani, R.; Karumanchi, S.A. Pathogenesis of preeclampsia. Curr. Opin. Nephrol. Hypertens. 2015, 24, 131-138. [CrossRef] [PubMed]

22. American Diabetes Association. 2. Classification and Diagnosis of Diabetes: Standards of Medical Care in Diabetes-2019. Diabetes Care 2019, 42, S13-S28. [CrossRef]

23. Sex-MeSH-NCBI. Available online: https://www.ncbi.nlm.nih.gov/mesh/68012723 (accessed on 24 April 2021).

24. Rodríguez-Bernal, C.L.; Rebagliato, M.; Iñiguez, C.; Vioque, J.; Navarrete-Muñoz, E.M.; Murcia, M.; Bolumar, F.; Marco, A.; Ballester, F. Diet quality in early pregnancy and its effects on fetal growth outcomes: The infancia y medio ambiente (childhood and environment) mother and child cohort study in Spain. Am. J. Clin. Nutr. 2010, 91, 1659-1666. [CrossRef] [PubMed]

25. Emond, J.A.; Karagas, M.R.; Baker, E.R.; Gilbert-Diamond, D. Better Diet Quality during Pregnancy Is Associated with a Reduced Likelihood of an Infant Born Small for Gestational Age: An Analysis of the Prospective New Hampshire Birth Cohort Study. J. Nutr. 2018, 148, 22-30. [CrossRef]

26. Rodríguez-Bernal, C.L.; Rebagliato, M.; Chatzi, L.; Carbonell, C.C.; Martos, C.; Ballester, F. Maternal Diet Quality and Pregnancy Outcomes. In Diet Quality; Springer: New York, NY, USA, 2013; pp. 65-79.

27. Gonzalez-nahm, S.; Hoyo, C.; Østbye, T.; Neelon, B.; Allen, C.; Benjamin-Neelon, S.E. Associations of maternal diet with infant adiposity at birth, 6 months and 12 months. BMJ Open 2019, 9, 1-7. [CrossRef] [PubMed]

28. Gresham, E.; Collins, C.E.; Mishra, G.D.; Byles, J.E.; Hure, A. Diet quality before or during pregnancy and the relationship with pregnancy and birth outcomes: The Australian Longitudinal Study on Women's Health. Public Health Nutr. 2016, 19, $2975-2983$. [CrossRef] 
29. Chatzi, L.; Garcia, R.; Roumeliotaki, T.; Basterrechea, M.; Begiristain, H.; Iñiguez, C.; Vioque, J.; Kogevinas, M.; Sunyer, J. Mediterranean diet adherence during pregnancy and risk of wheeze and eczema in the first year of life: INMA (Spain) and RHEA (Greece) mother-child cohort studies. Br. J. Nutr. 2013, 110, 2058-2068. [CrossRef]

30. Sebastiani, G.; Barbero, A.H.; Borrás-Novel, C.; Casanova, M.A.; Aldecoa-Bilbao, V.; Andreu-Fernández, V.; Tutusaus, M.P.; Martínez, S.F.; Roig, M.D.G.; García-Algar, O. The effects of vegetarian and vegan diet during pregnancy on the health of mothers and offspring. Nutrients 2019, 11, 557. [CrossRef]

31. Zhang, W. The Influence Of Maternal Nutrition Intake On The Birth Weight Of Newborns In Lanzhou, China. Mathers's Thesis, Yale University, New Haven, CN, USA, 2013.

32. Middleton, P.; Gomersall, J.C.; Gould, J.F.; Shepherd, E.; Olsen, S.F.; Makrides, M. Omega-3 fatty acid addition during pregnancy. Cochrane Database Syst. Rev. 2018, 2018, CD003402. [CrossRef] [PubMed]

33. Newberry, S.J.; Chung, M.; Booth, M.; Maglione, M.A.; Tang, A.M.; O’Hanlon, C.E.; Wang, D.D.; Okunogbe, A.; Huang, C.; Motala, A.; et al. Omega-3 Fatty Acids and Maternal and Child Health: An Updated Systematic Review. Evid. Rep. Technol. Assess. (Full. Rep.) 2016, 224, 1-826.

34. Eshak, E.S.; Okada, C.; Baba, S.; Kimura, T.; Ikehara, S.; Sato, T.; Shirai, K.; Iso, H. Maternal total energy, macronutrient and vitamin intakes during pregnancy associated with the offspring's birth size in the Japan Environment and Children's Study. Br. J. Nutr. 2020, 124, 558-566. [CrossRef] [PubMed]

35. Grieger, J.A.; Clifton, V.L. A review of the impact of dietary intakes in human pregnancy on infant birthweight. Nutrients 2015, 7, 153-178. [CrossRef] [PubMed]

36. Ludwig, D.S.; Currie, J. The association between pregnancy weight gain and birthweight: A within-family comparison. Lancet 2010, 376, 984-990. [CrossRef]

37. Goldstein, R.F.; Abell, S.K.; Ranasinha, S.; Misso, M.; Boyle, J.A.; Black, M.H.; Li, N.; Hu, G.; Corrado, F.; Rode, L.; et al. Association of gestational weight gain with maternal and infant outcomes: A systematic review and meta-analysis. JAMA 2017, 317, 2207-2225. [CrossRef] [PubMed]

38. Crume, T.L.; Brinton, J.T.; Shapiro, A.; Kaar, J.; Glueck, D.H.; Siega-Riz, A.M.; Dabelea, D. Maternal dietary intake during pregnancy and offspring body composition: The Healthy Start Study. Am. J. Obstet. Gynecol. 2016, 215, 609.e1-609.e8. [CrossRef] [PubMed]

39. Gala, U.M.; Godhia, M.L.; Nandanwar, Y.S. Effect of Maternal Nutritional Status on Birth Outcome. Int. J. Adv. Nutr. Health Sci. 2016, 4, 226-233. [CrossRef]

40. Bouthoorn, S.H.; van Lenthe, F.J.; Hokken-Koelega, A.C.S.; Moll, H.A.; Tiemeier, H.; Hofman, A.; Mackenbach, J.P.; Jaddoe, V.W.V.; Raat, H. Head Circumference of Infants Born to Mothers with Different Educational Levels; The Generation R Study. PLoS ONE 2012, 7, e39798. [CrossRef] [PubMed]

41. Hua, X.G.; Jiang, W.; Hu, R.; Hu, C.Y.; Huang, K.; Li, F.L.; Zhang, X.J. Large for gestational age and macrosomia in pregnancies without gestational diabetes mellitus. J. Matern. Neonatal Med. 2020, 33, 3549-3558. [CrossRef] [PubMed]

42. Romero-Martínez, M.; Shamah Levy, T.; Vielma-Orozco, E. Encuesta Nacional de Salud y Nutrición 2018-19: Metodología y perspectivas. Salud Publica Mex 2019, 61, 917-923. [CrossRef] [PubMed]

43. Baranowski, T. 24-Hour Recall and Diet Record Methods. In Nutritional Epidemiology; Willett, W.C., Ed.; Oxford University Press: New York, NY, USA, 2013; pp. 49-70.

44. Willett, W.C. Nature of Variation in Diet. In Nutritional Epidemiology; Hofman, A., Marmot, M., Samet, J., Savitz, D., Eds.; Oxford University Press: New York, NY, USA, 2013; p. 34.

45. Gibson, R. Measuring food consumption of individuals. In Principles of Nutrition Assessment; Gibson, R., Ed.; Oxford University Press: Dunedin, New Zealand, 2005; pp. 41-46. 